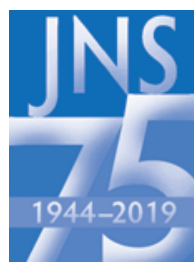

\title{
The evolution of surgical management for vertebral column tumors
}

\author{
JNSPG 75th Anniversary Invited Review Article \\ Jared Fridley, MD, and Ziya L. Gokaslan, MD \\ Department of Neurosurgery, Warren Alpert School of Medicine at Brown University, Providence, Rhode Island
}

Surgery for the resection of vertebral column tumors has undergone a remarkable evolution over the past several decades. Multiple advancements in surgical techniques, spinal instrumentation, technology, radiation therapy, and medical therapy have led to improved patient survival, function, and decreased morbidity. In this review, the authors discuss major changes in each of these areas in further detail.

https://thejns.org/doi/abs/10.3171/2018.12.SPINE18708

KEYWORDS spine tumor; primary tumor; secondary tumor; spinal radiosurgery; separation surgery; oncology

$\mathrm{T}$ HE treatment of vertebral column tumors has undergone significant transformation over the past several decades. Advances in surgical techniques, chemotherapy, radiation therapy, and the incorporation of technological innovations into the operating room have led to an overall shift in the management of patients with spine tumors, all with the goal of minimizing treatment-related morbidity. Perhaps the most significant changes have been the recent advances in spinal radiosurgery and cancer immunotherapy and the incorporation of patient and tumorspecific genomic and molecular information to personalize cancer therapy, particularly for metastatic disease.

While the goal of surgery for metastatic spine disease remains palliative, the typical poor prognosis given to these patients is trending toward a more optimistic outlook. With each advance, traditional prognostic scoring methods for metastatic spinal disease are becoming less accurate. Unlike metastases, most primary spine tumors continue to be treated primarily with surgery, but advances in surgical techniques that have incorporated principles from the treatment of long bone tumors have led to decreased tumor recurrence rates and, in some cases, a potential for cure. Research into adjuvant therapy for primary tumors is progressing, with many recent promising advances. In this review, we discuss the ongoing evolution of spine tumor treatment, particularly with regard to management of metastatic and primary spine tumors.

\section{Advances in Surgical Strategies}

The treatment of primary spine tumors remains primarily surgical. This simple fact belies the relatively recent change in how we resect these tumors. Principles for the treatment of long bone primary tumors developed and published by Enneking et al. ${ }^{19}$ in the 1980s were adapted for the spine by Weinstein and colleagues ${ }^{7}$ in the 1990s. The Weinstein-Boriani-Biagini system became an essential tool in presurgical planning for these tumors as it standardized the staging of primary spine tumors (Fig. 1). Specification of the exact tumor location in relation to the bony elements of the vertebra allows the surgeon to tailor the surgical approach, based on histology and location, which is particularly useful for tumors in which an en bloc resection is desired. While en bloc resection of primary spine tumors carries significant approach-related morbidity, the local recurrence rate and tumor-associated mortality can be significantly reduced. ${ }^{2,6}$ The Weinstein-BorianiBiagini classification also standardized the terminology

ABBREVIATIONS EBRT = external-beam radiation therapy; NOMS = neurological, oncological, mechanical, and systemic; SINS = spinal instability neoplasia score; SRS = stereotactic radiosurgery.

SUBMITTED December 1, 2018. ACCEPTED December 14, 2018.

INCLUDE WHEN CITING DOI: 10.3171/2018.12.SPINE18708. 


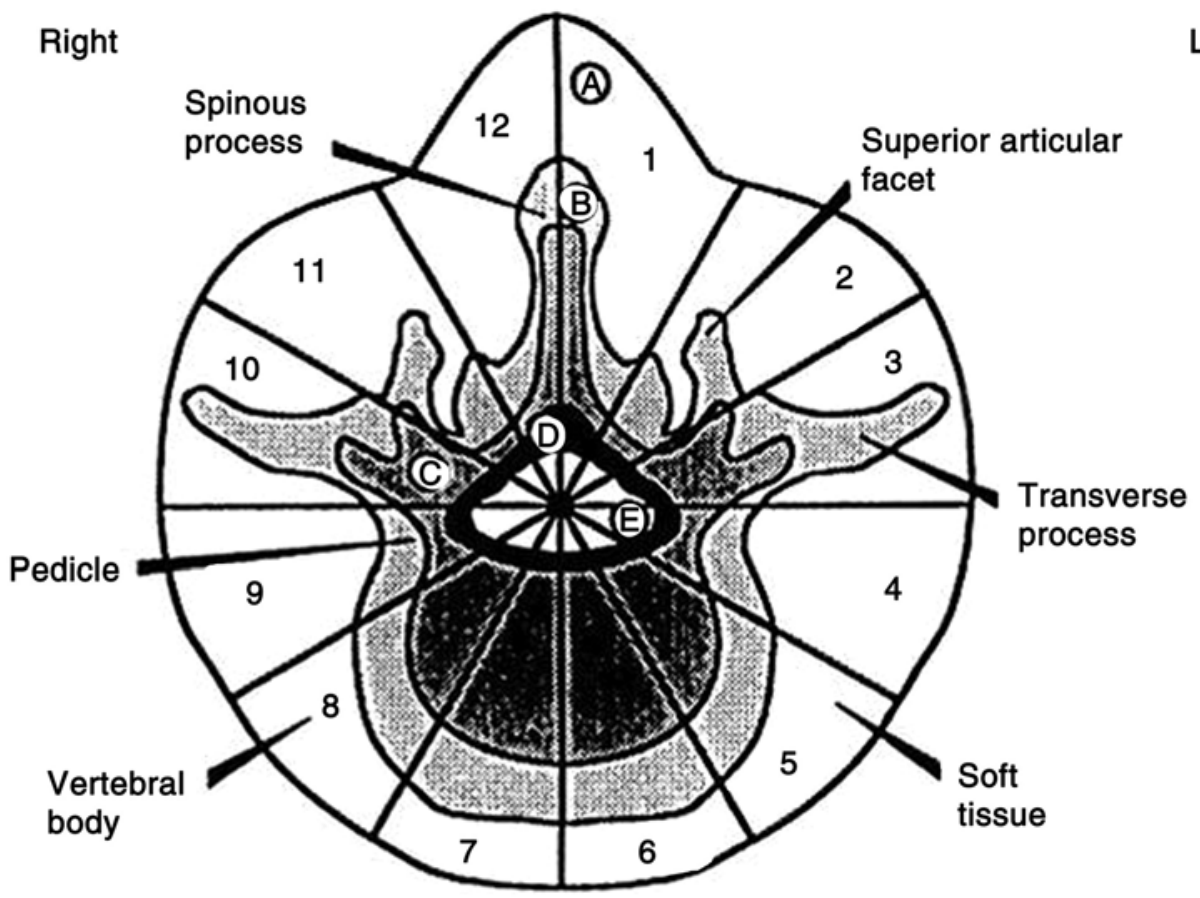
A. Extraosseous soft tissue
C. Intraosseous (deep)
E. Extraosseous (intradural)
B. Intraosseous (superficial)

\section{Extraosseous} (extradural)

FIG. 1. Weinstein-Boriani-Biagini classification for spinal tumors. Reproduced with permission from Boriani S, Weinstein JN, Biagini R: Primary bone tumors of the spine. Terminology and surgical staging. Spine (Phila Pa 1976) 22(9):1036-1044, 1997. https://journals.Iww.com/spinejournal/pages/default.aspx.

used when describing extent of resection, which allowed accurate comparison of treatment strategies between institutions and in the published literature.

Surgery for spinal metastases has perhaps undergone the most significant transformation in terms of surgical technique. Prior to the 1990 s many surgeons were performing either simple posterior bony decompression or primary external-beam radiation therapy (EBRT) for patients with metastatic epidural spine disease, causing cord compression. Young et al. ${ }^{61}$ demonstrated that these 2 treatments had similar efficacy in terms of pain relief, ambulation, and sphincter function, leading many to question the utility of a simple decompression. In addition, it was noted that many patients who underwent a laminectomy would develop kyphotic deformity over time, leading to significant patient morbidity. The landmark trial of Patchell et al., ${ }^{47}$ published in 2005, which excluded radiosensitive tumors, demonstrated that a direct circumferential decompression of the spinal cord with postoperative EBRT had significant benefit in terms of the ability to regain or preserve ambulatory function and reduced the need for corticosteroids and opioid analgesics. Subsequently, there was an increased focus on the benefit of surgical intervention with surgeons performing circumferential decompression supplemented with vertebral column reconstruction and posterior segmental instrumentation in increasing numbers.
Concurrent to the Patchell trial, work was also being done to study the utility of a new spinal radiation modality: spinal stereotactic radiosurgery (SRS), which built off the success of radiosurgery for brain metastases. In 2007, Gerszten et al..$^{24}$ published the results of a series of 500 metastases to the spine in 393 patients who underwent spinal radiosurgery; they excluded patients with neurological deficits or spinal instability. The results were particularly encouraging, with high rates of long-term pain control $(86 \%)$ and long-term tumor control (90\%). Radiosurgery will be discussed in more detail below, but suffice it to say that these results led again to a change in treatment paradigm for patients with metastatic spine disease.

The success of SRS led to many metastatic spine tumor patients being treated with primary radiation therapy rather than surgical intervention. Currently, the 2 main indications for primary surgical intervention are decompression of the spinal cord and stabilization of the spine if there is evidence of instability. While the former had demonstrated utility thanks in large part to the study of Patchell et al. ${ }^{47}$ spinal instability had not been well defined for the metastatic spine disease population. There had been significant heterogeneity in the literature regarding who might benefit from stabilization surgery, and there were no consensus guidelines available. In 2010, the Spine Oncology Study Group published the spinal instability neoplasia score (SINS), ${ }^{20}$ a scoring system to determine who may 
TABLE 1. The SINS for scoring spinal instability in patients with spine tumors

\begin{tabular}{|c|c|}
\hline Element of SINS & Score \\
\hline \multicolumn{2}{|l|}{ Location } \\
\hline Junctional (occiput-C2, C7-T2, T11-L1, L5-S1) & 3 \\
\hline Mobile spine (C3-C6, L2-L4) & 2 \\
\hline Semi-rigid (T3-T10) & 1 \\
\hline Rigid (S2-S5) & 0 \\
\hline \multicolumn{2}{|l|}{$\begin{array}{l}\text { Pain relief with recumbency and/or pain with movement/ } \\
\text { loading of the spine }\end{array}$} \\
\hline Yes & 3 \\
\hline No (occasional pain but not mechanical) & 1 \\
\hline Pain-free lesion & 0 \\
\hline \multicolumn{2}{|l|}{ Bone lesion } \\
\hline Lytic & 2 \\
\hline Mixed (lytic/blastic) & 1 \\
\hline Blastic & 0 \\
\hline \multicolumn{2}{|l|}{ Radiographic spinal alignment } \\
\hline Subluxation/translation present & 4 \\
\hline De novo deformity (kyphosis/scoliosis) & 2 \\
\hline Normal alignment & 0 \\
\hline \multicolumn{2}{|l|}{ Vertebral body collapse } \\
\hline$>50 \%$ collapse & 3 \\
\hline$<50 \%$ collapse & 2 \\
\hline No collapse with $>50 \%$ body involved & 1 \\
\hline None of the above & 0 \\
\hline \multicolumn{2}{|l|}{$\begin{array}{l}\text { Posterolateral involvement of the spinal elements (facet, } \\
\text { pedicle, or CV joint fraction or replacement with tumor) }\end{array}$} \\
\hline Bilateral & 3 \\
\hline Unilateral & 1 \\
\hline None of the above & 0 \\
\hline
\end{tabular}

$\mathrm{CV}=$ costovertebral.

The total score is used to classify a spine tumor as stable $(0-6)$, potentially unstable (7-12), or unstable (13-18). Reproduced with permission from Fisher CG, DiPaola CP, Ryken TC, et al: A novel classification system for spinal instability in neoplastic disease: an evidence-based approach and expert consensus from the Spine Oncology Study Group. Spine (Phila Pa 1976) 35(22):E1221-E1229, 2010. https://journals.Iww.com/spinejournal/pages/ default.aspx.

benefit from surgical consultation for tumor-related spinal instability (Table 1). This system has been shown to be reliable among both surgeons and nonsurgeons. , $^{3,8,22}$

To provide a treatment decision-making framework for spine oncology practitioners, Bilsky and Smith ${ }^{5}$ published the neurological, oncological, mechanical, and systemic (NOMS) system, which incorporates multiple factors, including 1) neurological examination, degree of spinal cord compression on imaging; 2) tumor sensitivity to radiation (oncological); 3) presence or absence of spinal instability; and 4) systemic burden of metastatic disease. This system has been refined, ${ }^{37}$ incorporating both radiosurgery and the SINS classification system into its decision-making algorithm. Its ease of use has led to its widespread adoption at many institutions. Under the NOMS framework, patients who should be considered for surgery are those who have high-grade spinal cord compression and/or spinal instability (Fig. 2). The high rate of local tumor control with SRS led to the concept of "separation surgery" in patients with high-grade metastatic epidural spinal cord compression. ${ }^{46}$ The goal of separation surgery is to limit the amount of tumor resection needed by creating a tumorfree margin around the thecal sac and using postoperative SRS for the remaining spinal tumor. By minimizing tumor resection, the hope is that surgical morbidity can be reduced, although this needs further study. Recently, Tatsui et al. ${ }^{53,55}$ published their experience using spinal laser interstitial thermotherapy (sLITT) for separation surgery, combined with percutaneous instrumentation. This technique minimizes surgical morbidity by treating epidural tumor with LITT rather than resection. This may be particularly useful in patients who either are poor surgical candidates or need to be given systemic treatment for their metastatic disease with minimal delay to treatment after surgery.

\section{Advances in Surgical Instrumentation and Technology}

Technological innovation in industry and academia has led to the incorporation of many different surgical adjuncts to decrease patient morbidity and improve surgical efficacy. Some of these innovations have become widely adopted, including screw-rod constructs, expandable titanium cages, kyphoplasty/vertebroplasty, computer-assisted spinal navigation, and intraoperative 3D fluoroscopy or $\mathrm{CT}$. The trend toward minimally invasive approaches has influenced the development trajectory in all these different areas.

Placement of surgical instrumentation in patients with vertebral column tumors is performed for the purpose of providing stability due to either pathologic fracture causing instability or tumor resection via a surgical approach that causes iatrogenic instability. Modern instrumentation today primarily consists of posterior screw-rod constructs $^{15,49}$ and various forms of vertebral column reconstruction (Fig. 3). Hook placement and wiring strategies are sometimes utilized, but the screw-rod technique has become the primary means of posterior stabilization. Screw-rod instrumentation can span multiple spinal segments, provides 3-column support, and is safe to place with minimal risk of neurological or vascular morbidity. 35,36

Intraoperative imaging and integrated computer-assisted spinal navigation can reduce the risk of hardware malposition and the need for subsequent revision. ${ }^{44,56}$ Today's spinal navigation systems primarily use intraoperative 3D fluoroscopy ${ }^{1}$ and $\mathrm{CT}^{62}$ to register the patient's spine to a fixed reference array attached to the patient. These systems are useful not only for assistance in screw placement but also can be useful during tumor resection. Spinal navigation can assist the spine surgeon in real time by defining the current extent of tumor resection in relation to surrounding bony structures. This is particularly useful in the event of significant distortion of normal anatomy by tumor. It is also possible with high-resolution imaging to identify 
tumor margins when attempting gross-total resection. For primary spinal tumors, we have fused preoperative MR images with intraoperative CT scans to create a 3D tumor model that is used with navigation to identify tumor margins and avoid tumor transgression (results pending publication). Spinal navigation is also particularly useful during mini-open exposures, as the amount of exposed anatomy available for intraoperative reference by the surgeon is reduced. Integration of navigation can potentially reduce patient morbidity during these approaches by localizing normal neurovascular structures without necessarily exposing them and minimizing the amount of soft-tissue dissection necessary to visualize the pathology of interest.

There are a range of options for vertebral column reconstruction after tumor resection that have been developed over the last several decades, with many viable solutions, including various polymethylmethacrylate constructs, ${ }^{45,60}$ mesh cylindrical cages, ${ }^{17}$ strut grafts, ${ }^{43}$ and expandable cages. ${ }^{18,52}$ Expandable cages, either titanium or polyetheretherketone (PEEK), have become perhaps the most popular method of vertebral column reconstruction following vertebral column tumor resection. Some advantages of expandable cages over other reconstruction options include their minimal insertion profile, ability to expand the cage in situ to create a solid fit in the bony defect, ability to correct sagittal plane deformity, and ability to insert autograft and/or allograft into the cage for osseous integration. Their smaller insertion profile allows relatively straightforward insertion from a posterior thoracic/lumbar approach, ${ }^{52}$ or mini-open thoracic/lumbar anterior approach, ${ }^{13}$ as well as an anterior cervical approach.

Another method of providing vertebral column support for pathologic vertebral body fractures is vertebroplasty or kyphoplasty. Vertebroplasty was first described in the late $1980 \mathrm{~s}^{23}$ followed by kyphoplasty a decade later. ${ }^{4,54}$ For each procedure, polymethylmethacrylate is injected into the fractured vertebral body via a percutaneous transpedicular approach. Kyphoplasty has the additional step of inflating a balloon in the vertebral body to create a cavity prior to cement injection, which can help reduce kyphotic deformity and increase the overall cement volume injected. Both procedures have been shown to improve pain scores (visual analog scale), reduce narcotic usage, and improve quality of life (SF-36). ${ }^{12}$ These procedures can be particularly useful as an adjunct prior to SRS, ${ }^{25}$ both to relieve mechanical back pain and provide mechanical stability. SRS has been shown to significantly increase the risk of vertebral body fracture at the treated level, ${ }^{51}$ particularly in patients with a high SINS score. ${ }^{38}$ Prophylactic cement augmentation can be considered in these high-risk patients.

\section{Advances in Radiotherapy}

As previously mentioned, SRS has changed the overall treatment paradigm for vertebral column tumors. Up until the late 20th century, radiation for spine tumors was performed using EBRT. ${ }^{27}$ While conventional EBRT is an effective modality for radiosensitive tumors such as lymphoma and myeloma, other solid tumors such as renal cell carcinoma do not respond as well. ${ }^{41}$ In 1995, Hamil-

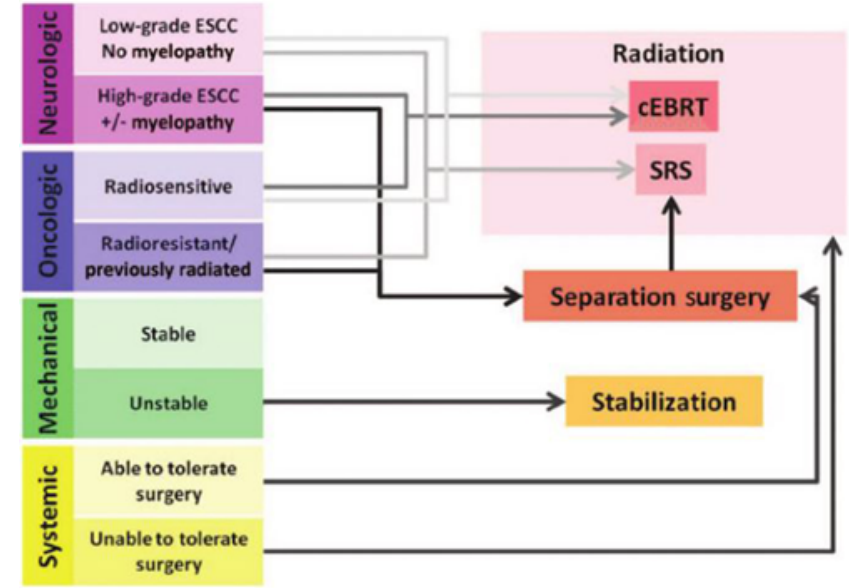

FIG. 2. Neurological, oncological, mechanical, and systemic (NOMS) framework for treatment of spine metastases. $\mathrm{CEBRT}=$ conventional EBRT; ESCC = epidural spinal cord compression. Reproduced with permission of Wiley, from The NOMS framework: approach to the treatment of spinal metastatic tumors. Laufer I, Rubin DG, Lis E, Cox BW, Stubblefield MD, Yamada Y, Bilsky MH. Oncologist 18(6):744-751, 2013; permission conveyed through Copyright Clearance Center, Inc. Figure is available in color online only.

ton et al. ${ }^{29}$ applied the principles of stereotactic radiation therapy developed by Lars Leksell to the treatment of 5 patients with spine metastasis using a linear accelerator and a spine-mounted frame. The encouraging early results led to further technological development to improve spine registration, tumor targeting, and radiation delivery accuracy. The CyberKnife system was the first advanced SRS platform applied to the treatment of spine tumors. ${ }^{50}$ There have been many iterations of this technology since then, with impressive local tumor control rates of over $90 \%$ when used as the primary treatment modality for metastatic spine tumors. ${ }^{24}$ For primary spine tumors, the results have been mixed, with most recommending SRS as either postoperative adjuvant treatment or primary therapy for those with unresectable or recurrent tumors., ${ }^{9,10,26,34}$

Proton-beam radiotherapy and more recently carbon ion radiotherapy are 2 other potential treatment options for primary spine tumors today. Proton-beam radiotherapy can deliver a large dose of energy with a sharply localized peak (Bragg peak), which means less radiation to surrounding normal tissues. ${ }^{39}$ This is particularly appealing for tumors of the spine, as it can be difficult to deliver high doses of radiation without injuring the spinal cord. Proton-beam radiotherapy has been shown to have local control rates for spinal chordomas and primary sarcomas at least as high or higher than that for photon-based radiotherapy. ${ }^{14,31,33}$ A recent meta-analysis comparing photon- and particle-based radiotherapy following surgery for chordoma suggested that proton radiotherapy may have an increased long-term overall survival compared with SRS..$^{63}$ Carbon ion radiotherapy, like proton radiotherapy, relies on charged particles to deliver energy to a target and has the same advantages as photon therapy in terms of dose drop-off. The primary advantage of carbon ion radiotherapy is the higher relative biological effectiveness versus both proton- and photon-based treatments. The 

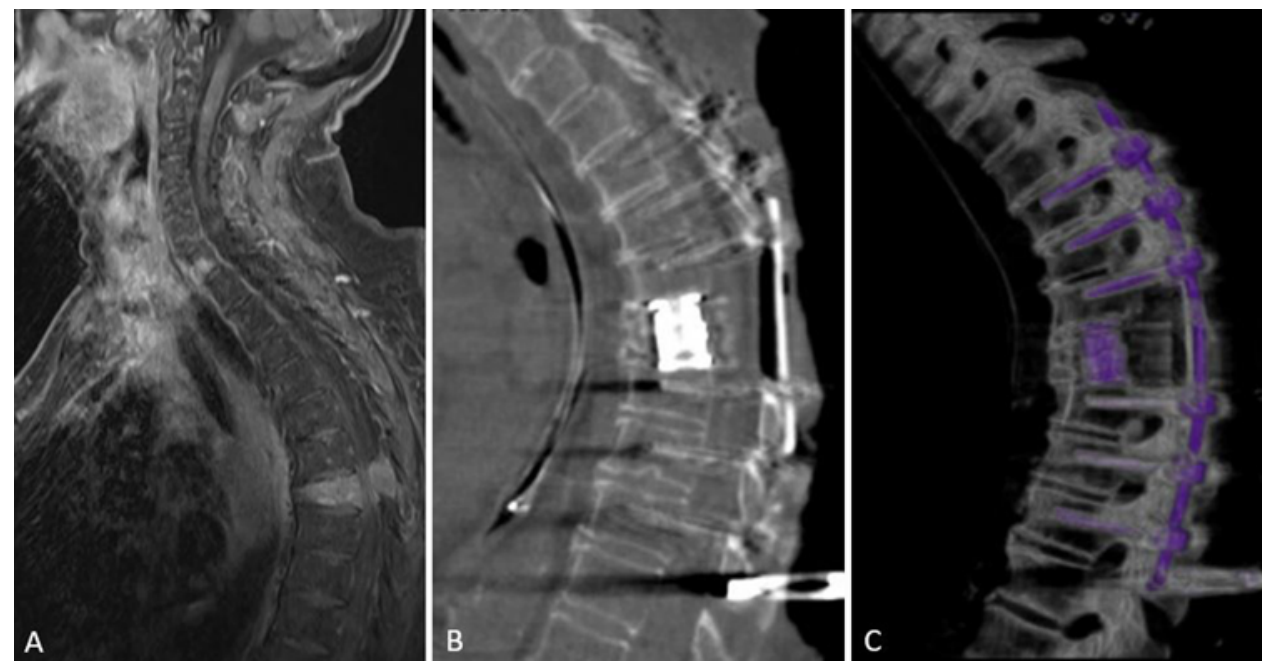

FIG. 3. Illustrative case of a 68-year-old woman with a thoracic spine metastasis causing epidural spinal cord compression seen on sagittal MRI of the thoracic spine with contrast (A). The patient underwent a posterior modified costotransversectomy with partial corpectomy, followed by posterior pedicle screw segmental instrumentation and expandable titanium cage vertebral column reconstruction. Postoperative sagittal CT scan of the thoracic spine showing the anterior reconstruction (B) and a 3D reconstruction showing both the anterior and posterior instrumentation (C). Figure is available in color online only.

5-year local control rates after carbon ion radiotherapy for patients with unresectable chordomas and sarcomas of the spine have been reported to be nearly $80 \% .^{32,42}$ Patients who undergo resection as the primary treatment may benefit from early postoperative particle radiation therapy versus salvage radiation therapy for recurrence. ${ }^{31}$

\section{Advances in Medical Therapy}

In the last decade, there have been multiple exciting developments in the medical treatment of cancer, particularly with development of monoclonal antibodies that affect signal transduction pathways and cellular checkpoints. Some tumors may be particularly susceptible to this approach due to their frequent infiltration with CD8-positive T cells, namely melanoma, lung, and kidney cancer. ${ }^{16}$ Several agents have significant tumor response rates and improved patient survival, namely inhibitors of $B R A F,{ }^{21,40}$ PD- $1,{ }^{28}$ PD-L1, ${ }^{48}$ and CTLA- $4 .{ }^{30} B R A F$ is a proto-oncogene that produces a protein involved in cell growth and is commonly mutated in melanoma patients. Patients with melanoma and a $B R A F$ mutation (V600E) given a $B R A F$ inhibitor have been shown to have significantly improved overall survival and progression-free survival versus traditional chemotherapy. ${ }^{11,21}$ Inhibition of CTLA-4 (cytotoxic T-lymphocyte antigen-4), an immune checkpoint, with the monoclonal antibody ipilimumab has been shown to improve survival in melanoma ${ }^{30}$ and is being investigated for use in a number of other cancers. Agents that inhibit the PD-1 checkpoint, or its ligand PD-L1, have been shown to improve survival in patients with non-small cell lung cancer, ${ }^{48}$ melanoma, ${ }^{28}$ and renal cell carcinoma. ${ }^{59}$

Cancer immunotherapy has altered how we view prognosis for patients with metastatic spinal disease, particularly for cancers previously thought to be resistant to either chemotherapy or radiation therapy. Scoring systems such as those by Tomita ${ }^{58}$ and Tokuhasi ${ }^{57}$ and their colleagues utilize the primary tumor site as one of the factors in determining prognosis. Considering the last decade's immunotherapy advances, the utility of these systems should be viewed skeptically. As patients with metastatic disease live longer, surgery technical considerations for surgery, such as construct durability, should be a consideration to prevent long-term complications, such as hardware failure, that may become more frequent.

\section{Conclusions}

The incorporation of these advances has led to hope for many patients, with improved survival for some and decreased surgical morbidity. Technological innovations have been occurring rapidly, as have discoveries in cancer biology and targeted therapies. If the last several decades have taught us one thing, it is that the future of surgical treatment for vertebral column tumors will likely not resemble treatment today.

\section{References}

1. Acosta FL Jr, Thompson TL, Campbell S, Weinstein PR, Ames CP: Use of intraoperative isocentric C-arm 3D fluoroscopy for sextant percutaneous pedicle screw placement: case report and review of the literature. Spine J 5:339-343, 2005

2. Amendola L, Cappuccio M, De Iure F, Bandiera S, Gasbarrini A, Boriani S: En bloc resections for primary spinal tumors in 20 years of experience: effectiveness and safety. Spine J 14:2608-2617, 2014

3. Arana E, Kovacs FM, Royuela A, Asenjo B, Pérez-Ramírez Ú, Zamora J: Spine Instability Neoplastic Score: agreement across different medical and surgical specialties. Spine J 16:591-599, 2016

4. Belkoff SM, Mathis JM, Deramond H, Jasper LE: An ex vivo biomechanical evaluation of a hydroxyapatite cement for use with kyphoplasty. AJNR Am J Neuroradiol 22:1212-1216, 2001

5. Bilsky M, Smith M: Surgical approach to epidural spinal 
cord compression. Hematol Oncol Clin North Am 20:13071317, 2006

6. Boriani S, Amendola L, Bandiera S, Simoes CE, Alberghini M, Di Fiore M, et al: Staging and treatment of osteoblastoma in the mobile spine: a review of 51 cases. Eur Spine $\mathbf{J}$ 21:2003-2010, 2012

7. Boriani S, Weinstein JN, Biagini R: Primary bone tumors of the spine. Terminology and surgical staging. Spine (Phila Pa 1976) 22:1036-1044, 1997

8. Campos M, Urrutia J, Zamora T, Román J, Canessa V, Borghero Y, et al: The Spine Instability Neoplastic Score: an independent reliability and reproducibility analysis. Spine J 14:1466-1469, 2014

9. Chang UK, Cho WI, Lee DH, Kim MS, Cho CK, Lee SY, et al: Stereotactic radiosurgery for primary and metastatic sarcomas involving the spine. J Neurooncol 107:551-557, 2012

10. Chang UK, Lee DH, Kim MS: Stereotactic radiosurgery for primary malignant spinal tumors. Neurol Res 36:597-606, 2014

11. Chapman PB, Hauschild A, Robert C, Haanen JB, Ascierto $\mathrm{P}$, Larkin J, et al: Improved survival with vemurafenib in melanoma with BRAF V600E mutation. N Engl J Med 364:2507-2516, 2011

12. Chi JH, Gokaslan ZL: Vertebroplasty and kyphoplasty for spinal metastases. Curr Opin Support Palliat Care 2:9-13, 2008

13. Chou D, Lu DC: Mini-open transpedicular corpectomies with expandable cage reconstruction. Technical note. J Neurosurg Spine 14:71-77, 2011

14. DeLaney TF, Liebsch NJ, Pedlow FX, Adams J, Dean S, Yeap BY, et al: Phase II study of high-dose photon/proton radiotherapy in the management of spine sarcomas. Int $\mathbf{J}$ Radiat Oncol Biol Phys 74:732-739, 2009

15. Dickman CA, Fessler RG, MacMillan M, Haid RW: Transpedicular screw-rod fixation of the lumbar spine: operative technique and outcome in 104 cases. J Neurosurg 77:860870,1992

16. Drake CG, Lipson EJ, Brahmer JR: Breathing new life into immunotherapy: review of melanoma, lung and kidney cancer. Nat Rev Clin Oncol 11:24-37, 2014

17. Dvorak MF, Kwon BK, Fisher CG, Eiserloh HL III, Boyd M, Wing PC: Effectiveness of titanium mesh cylindrical cages in anterior column reconstruction after thoracic and lumbar vertebral body resection. Spine (Phila Pa 1976) 28:902-908, 2003

18. Eleraky M, Papanastassiou I, Tran ND, Dakwar E, Vrionis FD: Comparison of polymethylmethacrylate versus expandable cage in anterior vertebral column reconstruction after posterior extracavitary corpectomy in lumbar and thoracolumbar metastatic spine tumors. Eur Spine J 20:1363-1370, 2011

19. Enneking WF, Spanier SS, Goodman MA: A system for the surgical staging of musculoskeletal sarcoma. Clin Orthop Relat Res (153): 106-120, 1980

20. Fisher CG, DiPaola CP, Ryken TC, Bilsky MH, Shaffrey CI, Berven $\mathrm{SH}$, et al: A novel classification system for spinal instability in neoplastic disease: an evidence-based approach and expert consensus from the Spine Oncology Study Group. Spine (Phila Pa 1976) 35:E1221-E1229, 2010

21. Flaherty KT, Puzanov I, Kim KB, Ribas A, McArthur GA, Sosman JA, et al: Inhibition of mutated, activated BRAF in metastatic melanoma. N Engl J Med 363:809-819, 2010

22. Fourney DR, Frangou EM, Ryken TC, Dipaola CP, Shaffrey CI, Berven SH, et al: Spinal instability neoplastic score: an analysis of reliability and validity from the spine oncology study group. J Clin Oncol 29:3072-3077, 2011

23. Galibert P, Deramond H, Rosat P, Le Gars D: [Preliminary note on the treatment of vertebral angioma by percutaneous acrylic vertebroplasty.] Neurochirurgie 33:166-168, 1987 (Fr)
24. Gerszten PC, Burton SA, Ozhasoglu C, Welch WC: Radiosurgery for spinal metastases: clinical experience in 500 cases from a single institution. Spine (Phila Pa 1976) 32:193-199, 2007

25. Gerszten PC, Germanwala A, Burton SA, Welch WC, Ozhasoglu C, Vogel WJ: Combination kyphoplasty and spinal radiosurgery: a new treatment paradigm for pathological fractures. J Neurosurg Spine 3:296-301, 2005

26. Gerszten PC, Ozhasoglu C, Burton SA, Welch WC, Vogel WJ, Atkins BA, et al: CyberKnife frameless single-fraction stereotactic radiosurgery for tumors of the sacrum. Neurosurg Focus 15(2):E7, 2003

27. Gilbert RW, Kim JH, Posner JB: Epidural spinal cord compression from metastatic tumor: diagnosis and treatment. Ann Neurol 3:40-51, 1978

28. Hamid O, Robert C, Daud A, Hodi FS, Hwu WJ, Kefford R, et al: Safety and tumor responses with lambrolizumab (antiPD-1) in melanoma. N Engl J Med 369:134-144, 2013

29. Hamilton AJ, Lulu BA, Fosmire H, Stea B, Cassady JR: Preliminary clinical experience with linear accelerator-based spinal stereotactic radiosurgery. Neurosurgery 36:311-319, 1995

30. Hodi FS, O'Day SJ, McDermott DF, Weber RW, Sosman JA, Haanen JB, et al: Improved survival with ipilimumab in patients with metastatic melanoma. N Engl J Med 363:711723, 2010

31. Holliday EB, Mitra HS, Somerson JS, Rhines LD, Mahajan A, Brown PD, et al: Postoperative proton therapy for chordomas and chondrosarcomas of the spine: adjuvant versus salvage radiation therapy. Spine (Phila Pa 1976) 40:544-549, 2015

32. Imai R, Kamada T, Araki N: Carbon ion radiation therapy for unresectable sacral chordoma: an analysis of 188 cases. Int J Radiat Oncol Biol Phys 95:322-327, 2016

33. Indelicato DJ, Rotondo RL, Begosh-Mayne D, Scarborough MT, Gibbs CP, Morris CG, et al: A prospective outcomes study of proton therapy for chordomas and chondrosarcomas of the spine. Int J Radiat Oncol Biol Phys 95:297-303, 2016

34. Jiang B, Veeravagu A, Feroze AH, Lee M, Harsh GR, Soltys $\mathrm{SG}$, et al: CyberKnife radiosurgery for the management of skull base and spinal chondrosarcomas. J Neurooncol 114:209-218, 2013

35. Karapinar L, Erel N, Ozturk H, Altay T, Kaya A: Pedicle screw placement with a free hand technique in thoracolumbar spine: is it safe? J Spinal Disord Tech 21:63-67, 2008

36. Kosmopoulos V, Schizas C: Pedicle screw placement accuracy: a meta-analysis. Spine (Phila Pa 1976) 32:E111-E120, 2007

37. Laufer I, Rubin DG, Lis E, Cox BW, Stubblefield MD, Yamada Y, et al: The NOMS framework: approach to the treatment of spinal metastatic tumors. Oncologist 18:744751,2013

38. Lee SH, Tatsui CE, Ghia AJ, Amini B, Li J, Zavarella SM, et al: Can the spinal instability neoplastic score prior to spinal radiosurgery predict compression fractures following stereotactic spinal radiosurgery for metastatic spinal tumor? A post hoc analysis of prospective phase II single-institution trials. J Neurooncol 126:509-517, 2016

39. Levin WP, Kooy H, Loeffler JS, DeLaney TF: Proton beam therapy. Br J Cancer 93:849-854, 2005

40. Long GV, Stroyakovskiy D, Gogas H, Levchenko E, de Braud F, Larkin J, et al: Combined BRAF and MEK inhibition versus BRAF inhibition alone in melanoma. N Engl J Med 371:1877-1888, 2014

41. Maranzano E, Latini P: Effectiveness of radiation therapy without surgery in metastatic spinal cord compression: final results from a prospective trial. Int J Radiat Oncol Biol Phys 32:959-967, 1995

42. Matsumoto K, Imai R, Kamada T, Maruyama K, Tsuji H, 
Tsujii H, et al: Impact of carbon ion radiotherapy for primary spinal sarcoma. Cancer 119:3496-3503, 2013

43. McCormick PC: Surgical management of dumbbell and paraspinal tumors of the thoracic and lumbar spine. Neurosurgery 38:67-75, 1996

44. Meng XT, Guan XF, Zhang HL, He SS: Computer navigation versus fluoroscopy-guided navigation for thoracic pedicle screw placement: a meta-analysis. Neurosurg Rev 39:385391, 2016

45. Miller DJ, Lang FF, Walsh GL, Abi-Said D, Wildrick DM, Gokaslan ZL: Coaxial double-lumen methylmethacrylate reconstruction in the anterior cervical and upper thoracic spine after tumor resection. J Neurosurg 92 (2 Suppl):181-190, 2000

46. Moussazadeh N, Laufer I, Yamada Y, Bilsky MH: Separation surgery for spinal metastases: effect of spinal radiosurgery on surgical treatment goals. Cancer Contr 21:168-174, 2014

47. Patchell RA, Tibbs PA, Regine WF, Payne R, Saris S, Kryscio RJ, et al: Direct decompressive surgical resection in the treatment of spinal cord compression caused by metastatic cancer: a randomised trial. Lancet 366:643-648, 2005

48. Reck M, Rodríguez-Abreu D, Robinson AG, Hui R, Csôszi T, Fülöp A, et al: Pembrolizumab versus chemotherapy for PD-L1-positive non-small-cell lung cancer. N Engl J Med 375:1823-1833, 2016

49. Roy-Camille R, Saillant G, Mazel C: Internal fixation of the lumbar spine with pedicle screw plating. Clin Orthop Relat Res (203):7-17, 1986

50. Ryu SI, Chang SD, Kim DH, Murphy MJ, Le QT, Martin DP, et al: Image-guided hypo-fractionated stereotactic radiosurgery to spinal lesions. Neurosurgery 49:838-846, 2001

51. Sahgal A, Whyne CM, Ma L, Larson DA, Fehlings MG: Vertebral compression fracture after stereotactic body radiotherapy for spinal metastases. Lancet Oncol 14:e310-e320, 2013

52. Shen FH, Marks I, Shaffrey C, Ouellet J, Arlet V: The use of an expandable cage for corpectomy reconstruction of vertebral body tumors through a posterior extracavitary approach: a multicenter consecutive case series of prospectively followed patients. Spine J 8:329-339, 2008

53. Tatsui CE, Belsuzarri TA, Oro M, Rhines LD, Li J, Ghia AJ, et al: Percutaneous surgery for treatment of epidural spinal cord compression and spinal instability: technical note. Neurosurg Focus 41(44):E2, 2016

54. Theodorou DJ, Theodorou SJ, Duncan TD, Garfin SR, Wong WH: Percutaneous balloon kyphoplasty for the correction of spinal deformity in painful vertebral body compression fractures. Clin Imaging 26:1-5, 2002

55. Thomas JG, Al-Holou WN, de Almeida Bastos DC, Ghia AJ, Li J, Bishop AJ, et al: A novel use of the intraoperative MRI for metastatic spine tumors: laser interstitial thermal therapy for percutaneous treatment of epidural metastatic spine disease. Neurosurg Clin N Am 28:513-524, 2017
56. Tian NF, Huang QS, Zhou P, Zhou Y, Wu RK, Lou Y, et al: Pedicle screw insertion accuracy with different assisted methods: a systematic review and meta-analysis of comparative studies. Eur Spine J 20:846-859, 2011

57. Tokuhashi Y, Uei H, Oshima M, Ajiro Y: Scoring system for prediction of metastatic spine tumor prognosis. World J Orthop 5:262-271, 2014

58. Tomita K, Kawahara N, Kobayashi T, Yoshida A, Murakami H, Akamaru T: Surgical strategy for spinal metastases. Spine (Phila Pa 1976) 26:298-306, 2001

59. Topalian SL, Hodi FS, Brahmer JR, Gettinger SN, Smith DC, McDermott DF, et al: Safety, activity, and immune correlates of anti-PD-1 antibody in cancer. N Engl J Med 366:24432454, 2012

60. Wang JC, Boland P, Mitra N, Yamada Y, Lis E, Stubblefield $\mathrm{M}$, et al: Single-stage posterolateral transpedicular approach for resection of epidural metastatic spine tumors involving the vertebral body with circumferential reconstruction: results in 140 patients. Invited submission from the Joint Section Meeting on Disorders of the Spine and Peripheral Nerves, March 2004. J Neurosurg Spine 1:287-298, 2004

61. Young RF, Post EM, King GA: Treatment of spinal epidural metastases. Randomized prospective comparison of laminectomy and radiotherapy. J Neurosurg 53:741-748, 1980

62. Zausinger S, Scheder B, Uhl E, Heigl T, Morhard D, Tonn JC: Intraoperative computed tomography with integrated navigation system in spinal stabilizations. Spine (Phila Pa 1976) 34:2919-2926, 2009

63. Zhou J, Yang B, Wang X, Jing Z: Comparison of the effectiveness of radiotherapy with photons and particles for chordoma after surgery: a meta-analysis. World Neurosurg 117:46-53, 2018

\section{Disclosures}

The authors report no conflict of interest concerning the materials or methods used in this study or the findings specified in this paper.

\section{Author Contributions}

Conception and design: Gokaslan. Acquisition of data: Fridley. Drafting the article: Fridley. Approved the final version of the manuscript on behalf of both authors: Gokaslan.

\section{Correspondence}

Ziya L. Gokaslan: Warren Alpert Medical School of Brown University, Rhode Island Hospital, Providence, RI. ziya_gokaslan@ brown.edu. 